\section{Emerging Approaches to Setting Faculty Salaries}

\section{James C. Hearn}

James C. Hearn is professor and chair in the Department of Educational Policy and Administration, College of Education, University of Minnesota. Address: 330 Wulling Hall, University of Minnesota, 86 Pleasant Street, Minneapolis, MN 55455-0221. Phone: 612/624-1006 Fax: 612/ 624-3377. E-Mail: <hearn001@tc.umn.edu>.

$\mathrm{U}$ ntil recently, faculty salaries were largely a taboo topic in the public discourse about the university. That tradition may be ending, however. Salaries are a prominent feature of the reward systems under which academic work is done, and not surprisingly, they are also becoming a prominent topic in discussions about productivity on campus. Consequently, there is a growing need to examine salary data and policies.

\section{Contemporary Salary Data}

No longer regularly losing ground to inflation, salary differences between academics and other professionals in the United States have grown substantially in the last two decades. Of course, salary differences by field and gender remain substantial. Full professors of education typically earn about $\$ 20,000$ less than do full professors of engineering at four-year institutions, and women faculty earn appreciably less than men. ${ }^{1}$ The continuing deficit in women's earnings is due mainly to their disproportionate representation in lower-paying fields. However, there is also a notable deficit for women within ranks in given fields, perhaps implying gender discrimination. ${ }^{2}$

Until recently, faculty salaries were largely a taboo topic in the public discourse about the university.

Demography is critical in overall salary outlays. Employing a more senior faculty generally means higher average salaries and therefore more costs. Because the large number of faculty hired in the expansionary years of the 1960s and 1970s will be retiring in increasing numbers in the coming decade, universities may anticipate some savings through replacement hires at the junior level, the canceling of lines, and the hiring of less costly part-time and non-tenure-track faculty.

\section{Improving Salary Policies}

The productivity of individual faculty members is not always appropriately reflected by their salaries. Institutions are often loathe to differentiate meaningfully the salary increments of those who perform well and those who perform poorly. Most institutions in the United States award annual salary changes in the form of small percentage increments, and even aggressive differentiation within restricted percentage ranges (typically 2 to 6 percent) does not address substantial performance differences. Indeed, gains of 3 percent for highly paid but poorly performing senior professors may be greater in dollar terms than gains of 6 percent among high-performing but lower-paid junior faculty. In such a scenario, not at all unusual in the United States, the salary advantage of the person performing more poorly is actually increased.

\section{More closely linking salaries and per- formance is only one of the issues fac- ing those seeking to improve salary policies.}

More closely linking salaries and performance is only one of the issues facing those seeking to improve salary policies. To address the daunting complexities of salary policy, institutions must first develop overarching principles for evaluating their salary systems. Among the important principles to be addressed is whether the system is efficient. That is, does it take an appropriate level of time and other resources to operate? Further, is the system well understood? Are the procedures for salary determination fair? Are the outcomes of salary determination equitable? Does the system allow adequate flexibility in response to potential crises and special cases? Does the system fit the strategies, politics, and culture of the campus? Is the system assessed and evaluated on a regular basis?

Beyond guiding principles lies institutional policy. Specific policy recommendations are rarely appropriate for every institution and, not surprisingly, there are no magic formulas for improving salary policies. It may be useful, however, to highlight some policy choices facing contemporary leaders.

Choice 1: De-emphasizing the External Marketplace

A fundamental aspect of salary policy is the stance regarding the role of the external marketplace. Salary compression 
within fields, salary dispersion across fields, gender differences in salaries, and the willingness to make sizable retention counteroffers to current faculty being recruited by other institutions are factors that involve dislocations driven by external markets. Some institutions may choose to de-emphasize the influences of the external marketplace on their internal salary structures, despite the potential losses of faculty in externally favored fields.

\section{Choice 2: Adopting the "Core Salary" Approach}

Some institutional leaders have proposed breaking up a faculty member's traditional base salary into a guaranteed "core" component and a second "flexible" component. While the first portion of salary would be assured, the second would vary annually depending on the institutional revenues generated by the faculty member. This approach in universities would represent a radical change. Institutional flexibility would be improved but professors' sense of community and wellbeing might be threatened.

\section{Choice 3: Tying Annual Salary Changes to Annual Performance}

Any system closely linking pay with performance can create wide salary advantages for those performing well and actual salary loss for those performing poorly. Universities have historically been reluctant to move in that direction. Efficiency in salary systems can mean wider dispersion in salary levels. Under such a system, institutions have to decide whether such a scenario would result in unacceptable faculty discomfort.

\section{Choice 4: Pursuing Internal Consistency in the Determination of Salaries}

When criteria and processes for salary advancement shift over time and vary greatly across units, women, minorities, and others may be disadvantaged. Still, some flexibility in reward systems is necessary. For example, music differs notably from physics in its standard markers of scholarly success. Institutions must be wary of forcing one model unbendingly onto all fields, but must also monitor the equity of decentralized systems.

\section{Choice 5: Welcoming Faculty Participation in Determination} of Merit-Based Salary Increases

When faculty participate in awarding individual merit salary increases, decision quality may be improved and administrators may be more protected from charges of favoritism. On the other hand, those participating may not always reflect the core values of the institution and troubling privacy concerns can arise.

Choice 6: Facilitating Public Scrutiny of Salaries Releasing information about relative salary levels raises legitimate privacy concerns and threatens organizational harmony. In a setting committed to public service and democratic and scientific ideals, however, it is somewhat incongruous to argue that professionals benefit from being deprived of information.

\section{The productivity of individual faculty members is not always appropriately reflected by their salaries.}

\section{Choice 7: Elevating Teaching and Public Service as Criteria} for Salary Adjustments

In U.S. universities, research accomplishments are the primary factor in determining salary awards. Under the prodding of Ernest Boyer and others, however, this primacy of research over teaching and service has been challenged in recent years. ${ }^{3}$ It is unclear whether reforms will succeed, but many institutions are energetically considering this choice.

\section{Conclusion}

Salaries are only one piece in a mosaic of elements comprising the environment of faculty productivity. Alone, salaries are neither the most important motivators for faculty in universities nor the most uplifting of topics. Yet, reforming faculty reward systems without close attention to salaries makes little sense. To ignore salaries is to ignore not only a critical factor in institutional budgets and in public critiques of higher education but also a noteworthy element of professors' satisfaction.

While problems abound, the potential for using salaries as a lever for changing faculty behavior is perhaps more significant than many observers realize. For many institutions, their futures are highly dependent on their salary structures. Clearly compelling reasons exist for academic leaders to energetically focus on the topic.

\section{Notes}

1. "Not so Bad," Academe 82, no. 2 (March/April, 1996): 14-22.

2. "Not so Good," Academe 82, no. 2 (March/April, 1997): 12-88.

3. Ernest L. Boyer, Scholarship Reconsidered: Priorities of the Professoriate (Princeton, N.J.: Carnegie Foundation for the Advancement of Teaching, 1990).

This article is a shortened version of "Faculty Salary Structures in Research Universities: Implications for Productivity," in Faculty Productivity: Facts, Fictions, and Issues, ed. W. G. Tierney (New York: Garland, forthcoming). 